IRSTI 31.23.99; 31.23 .01

\author{
${ }^{1}$ M. Gharibi.Tehrani, ${ }^{1}$ A.H. Elhamirad, ${ }^{2 *}$ E. Azarpazhooh, \\ ${ }^{1}$ A. Pedramnia, ${ }^{2}$ P. Sharayei \\ ${ }^{1}$ Department of Food Science \& Technology, Sabzevar Branch, Islamic Azad University, Sabzevar, Iran \\ ${ }^{2}$ Agricultural Engineering Research Department, Khorasan Razavi Agricultural and \\ Natural Resources Research and Education Center, AREEO, Mashhad, Iran \\ *e-mail:Azarpazhooh@gmail.com
}

\title{
Natural valuable compound extraction from onion by-products using a pulsed electric field
}

\begin{abstract}
Onion by-products, a waste generated from fruit processing industry, is a potential source of phenolic compounds that are known for their anti-oxidative properties. The influence of pulsed electric field (PEF) treatment on the bioactive compounds from onion by-products at different pulse voltage (PV); 2000, 4000, 6000Vand number of pulse (NP); 40, 50, 60 has been investigated. Response surface methodology, based on a Face-Centered Experimental Design (FCED) was used to determine optimal PEF treatment and optimize extraction yield, antioxidant strength, total phenolic compound (TPC), and quercetin content. The experimental data were fitted to a second-order polynomial equation and also profiled into the corresponding 3-D contour plots. Optimal extraction conditions were as follows:PV were 4102.97 V and and NP 51.43. Under these conditions, TPC, DPPH, FRAP,Quercetin and extraction yield were $48.912 \pm 6 \mathrm{mg} / \mathrm{kg}, 50.366$ $\pm 1 \%, 465.414 \pm 5 \mu \mathrm{mFe} 2 / 1,31.761 \pm 0.5 \mathrm{mg} / 100 \mathrm{~g}$ and $88.107 \pm 1 \%$; respectively and matching well with the predicted value. The results demonstrated that PEF could be a very effective method for continuous extraction of natural compounds.
\end{abstract}

Key words: antioxidant, phenolic, quercetin, extract, onion, optimal.

\section{Introduction}

Onion (Allium cepa L.) has been used as a food and as a treatment for many diseases since ancient history. Allium family plants are major sources of many phenolic and flavonoid compounds in the diet $[1 ; 2]$. Flavonoids in food and other phenolic compounds, such as quercetin flavonols, kaempferol, and myricetin, have antioxidant activities and antibacterial [3].

Considering abundant quantities of onions annually are disposed of as waste from the process in plant protein products, and as an important nutritional source for the production of natural additives with antioxidant and antimicrobial properties, also can lead to problems such as wasting this national capital and disposing of these wastes. Besides, the agricultural by-products in food processing are increased; one of the applications of these materials is the extraction of flavonoids from fruits and vegetables such as apples, onions, and citrus fruits, which have antioxidant activities [4], especially, onion by-products that are quercetin-rich antioxidant and as retrieval raw materials. [5]. Extraction with conventional methods, including soaking, maceration, boiling, grinding, soxhlet extraction and etc [6;7], have limitations like long processing time, low EY, high solvent consumption and thermal degradation of thermo-unstable active compounds [8] To prevail over the defects of conventional extraction processes mentioned above, several novel techniques have been researched, including $\mathrm{UAE}^{1}, \mathrm{PEF}$-assisted extraction, $\mathrm{MAE}^{2}, \mathrm{SFE}^{3}$, and etc $[9 ; 10]$. The advantages of developed methods were substantiated by comparing with conventional extraction techniques, such as soxhlet and maceration methods [11]. PEF process is a technique of green extraction, which has created increased interest in recent years due to its economic efficiency in foodstuff. The basis of the PEF technique is extracting intracellular materials from a plant for the application of electrical energy using an electric field and the formation of a pore in the cell membrane, which was called electroporation [12]. The external electric field creates a membrane transition potential that is larger

\footnotetext{
${ }^{1}$ - ultrasound-assisted extraction

2 - microwave assisted extraction

${ }^{3}$ - supercritical fluid extraction
} 
than the natural potential of the cell, and when the overall membrane potential reaches a critical level, the membrane ruptures, which is reversible and irreversible. The extraction process of intracellular materials from the plant can be used only in the irreversible rupture that facilitates the release of water and transfer of heat or osmosis material from permeability phenomenon. One of the most important achievements of this method was to accelerated the extraction process and speed, increased efficiency, environmentally-friendly, save energy, preservation material qualification properties [13], also extracted valuable compounds from softened plant material [14] The results of the researchers demonstrated that PEF-assisted extraction was increased the of polyphenol extracts (67-75\%) in Chardonnay grape [15]. It also raised the antioxidant activity and the TPC of the extract of grape wastes [16].

Extraction of polyphenols in orange peel using the PEF showed that this technique can be used as a mild extraction process to improve the process of extraction of polyphenols from fresh orange peel, also increased the antioxidant capacity of the extract, and reduced the time of extraction without the need for organic solvents [17]. PEF was used to extract polyphenols from plant wastes such as anthocyanidins from red grape pulp, flavonols from onion by-products and phenolic acid from potato peel and polyphenols from apple pulp [18].

The aim of this study was to investigate the use of PEF process for extraction bioactive compounds from yellow onion by-product and determine the independence valuables such as the PV and the NP required achieving maximum cell degradation and ease of mass transfer for more extraction, also, Response Surface Methodology(RSM) and the FCED were used to optimize and comprise of total phenolic compound, strength of antioxidant, quercetin content and EY the onion by-products extracts with Conventional solid-liquid extraction.

\section{Materials and methods}

\section{Raw materials}

Onion by-products (Allium cepa L.), as an unacceptable production, were manually gathered from Fruit Bazar, Mashhad, Iran in the month of July of 2017. The samples were stored in cold storage at $4^{\circ}$ $\mathrm{C}$ for further analysis.

\section{Chemical and Reagents}

All chemicals and reagents used in this study, were analytical grade consisting of 2,4,6 tris(2-
pyridyl)-s-triazine(TPTZ), Folin-Ciocalteu(FC), gallic acid, DPPH \& quercetin were provided from Sigma-Aldrich (St. Louis, MO), chemical and organic solvents were purchased from Merck (Darmstadt, Germany).

\section{Extraction procedures}

\section{Conventional solid-liquid extraction}

Extraction of onion by-products with ethanol was performed. Samples of onion wastes (1-10 v/wt) were mixed with $70 \%$ ethanol at temperatures $(25,30$ and $\left.35^{\circ} \mathrm{C}\right)$, and times (12, 18 and 24 hours) by magnetic stirrer with a circumference of about $230 \mathrm{rpm}$. The extracted extracts were separated using Whatman filter paper No. 1 and vacuum pump from plant solids. Then, in order to remove the solvent, the extracts were obtained in a rotary machine, EI141 vapor Rotary, (Buchi, Switzerland) under vacuum distillation. The extracts transferred to glass plates and heated to $45^{\circ} \mathrm{C}$ in constant temperature until they reached constant weight. Then, plates were closed and covered with aluminum foil and stored in a freezer at $-18^{\circ} \mathrm{C}$ for analysis [19].

\section{PEF-assisted extraction}

The PEF processing of onion by-products was conducted using an apparatus (constructed by Sib Food.Tech, Germany). This system created electricity flow $20 \mathrm{KV}$, logarithmic pulses and a power supply electric pulses $(220-240 \mathrm{~V}$, at the frequency of $50 \mathrm{~Hz})$, Transmitted electricity to a power supply, There, a linear flow of electrical energy was transmitted to a capacitor series and the energy stored in the capacitors was pulled out by the two electrodes with the pulse key.

Before the extraction procedure, for carrying out extraction, $200 \mathrm{~g}$ sample of onion by-product was weighed and the mixture consisting of water and ethanol was subjected to PEF for different PV (2000, $4000,6000 \mathrm{~V})$ and the NP $(40,50,60)$. when the extraction process was completed, the treatments were filtered with Whatman filter paper No 1, (Whatman International Ltd, UK) and placed at room temperature for 48 hours, until the solvent was removed, concentrated and the concentrate was dried. Finally, the dried samples were prepared for analysis.

\section{Statistical analysis}

Experimental design

In order to study the effect of extraction process on antioxidant activity of onion by-products, FCED Response Surface Methodology RSM and a design Expert Software Version 8.0.7.1(Minneapolis, USA) 
was used to determine the effect of two independent parameters in extraction using a PEF $\left[\mathrm{PV}\left(\mathrm{X}_{\mathrm{i}}\right)\right.$ and NP $\left.\left(X_{j}\right)\right]$ at three levels $(-1,0,+1)$, five replicates at the central points on the EY \%, TPC;mg gallic acid equivalents per $\mathrm{kg}$, FRAP; $\mu$ mol $\mathrm{Fe}^{2+} / \mathrm{g}$, DPPH $\%$. The coded and actual levels of each of the variables are given in Table 1.

Table 1 - Valuable codes, actual value and independence variables used in FCED

\begin{tabular}{|c|c|c|}
\hline $\begin{array}{c}\text { Independence } \\
\text { variables }\end{array}$ & Valuable Codes & Actual values \\
\hline $\mathrm{PV}$ & $-1,0,+1$ & $2000,4000,6000 \mathrm{~V}$ \\
\hline $\mathrm{NP}$ & $-1,0,+1$ & $40,50,60$ \\
\hline
\end{tabular}

\section{Modeling of variables}

The statistical significance of the regression equations was performed by variance analysis (ANOVA) to obtain the response. In order to evaluate the validity of fitted models accuracy, lack of fit, CV, R-square, R-square (adj), model and P-coefficients were used to Design Expert Software. To illustrate the relationship between each of the dependent variables in the regression model with independent variables, their graphs were plotted by this software. Various responses were the conclusion of various interactions of independent variables; the second order polynomial regression equation was fitted to the experimental data of all responses, (Eq.1) [20].

$$
Y=\beta_{0}+\sum_{j=1}^{k} \quad \beta_{j} X_{j}+\sum_{j=1}^{k} \quad \beta_{j j} X_{j j}+\sum_{i=1}^{j 1-} \quad \sum_{j=2}^{k} \quad \beta_{i j} X_{i} X_{j}+\varepsilon
$$

Y: predicted response, $\beta_{0}$ : constant, $\beta \mathrm{i}$ : linear coefficient, $\beta \mathrm{jj}$ : interaction coefficients, $\mathrm{Xi}$ and $\mathrm{Xj}$ : independent variables, $\varepsilon$ : noise or error

\section{Measurement of TPC}

TPC of onion extracts was measured by the Folin-Ciocalteu method [21]. TPC Data were presented as mg gallic acid equivalents per kilogram dry weight. For the analysis, sample solution of $100 \mu 1$ was mixed (100 $\mathrm{mg}$ of the sample in $10 \mathrm{ml}$ of methanol), and then $2.5 \mathrm{ml}$ reagent of Folin-Ciocalteu was added and was remained at room temperature, for 8 min to react. Then, $1.5 \mathrm{ml}$ of sodium carbonate $(20 \%$ $\mathrm{w} / \mathrm{v}$ ) was stirred to the aqueous phase and kept in a dark place at room temperature for $30 \mathrm{~min}$. the absorbance of the sample was calculated at $765 \mathrm{~nm}$ in conformity with the following formula (Eq.2). Water and reagent mixtures were used as a blank. Standard gallic acid solutions were prepared in methanol at concentrations ranging from 0.04 to $0.4 \mathrm{mg} / \mathrm{ml}$ (Eq.2).

$$
\mathrm{Y}=1.0776 \mathrm{X}+0.2644 \mathrm{X}+0.0099
$$

$\mathrm{X}$ : absorbance in $765 \mathrm{~nm}$

$$
\mathrm{P}=\frac{\mathrm{Y}}{\mathrm{W}} * 1000
$$

P: TPC (mg gallic acid per $\mathrm{Kg}$ )

Y: TPC (mg gallic acid per $\mathrm{ml}$ )

W: Sample Weight $(\mathrm{g})$

\section{Determination of antioxidant capacity}

Antioxidant capacity was measured by DPPH free radical scavenging capacity [22] and FRAP [23].

\section{$D P P H$ free radical scavenging assay}

The DPPH free radical-scavenging activity of onion by-products extracts was evaluated by Ersus and Urdagol [22]. The solution of $0.006 \%$ DPPH free radical reagent in methanol was prepared. The test tubes were stored in a dark place for $30 \mathrm{~min}$. Finally, Discolorations were measured at an absorbance of $512 \mathrm{~nm}$ by using a UV-1601 spectrophotometer (Shimadzu, Kyoto, Japan) in the following formula (Eq.3). All of the analyses were done in triplicate.

$$
\% \mathrm{DPPH}=\frac{\text { A count }- \text { Asample }}{\text { Acount }} * 100
$$

$A_{\text {count }}:$ Absorbance of control

$\mathrm{A}_{\text {sample }}^{\text {count }}$ : Absorbance of sample

\section{Determination of FRAP assay}

FRAP was determined using 2, 4, 6-tripyridyl-striazine (TPTZ) by the method of Benzie and Strain 1996 [23]. This method is according to the reduction of the ferric tripyridyltriazine complex to its ferrous, colored form in the presence of antioxidants. The stock solutions were consist of, $300 \mathrm{mM}$ acetate buffer (pH3.6), 10mM TPTZ solution in 40Mm HCl, and $20 \mathrm{mM} \mathrm{FeCl} \cdot 6 \mathrm{H}_{2} \mathrm{O}$ solution. The analysis solutions were made freshly by stirring $25 \mathrm{ml}$ of acetate buffer, $2.5 \mathrm{ml}$ of TPTZ solution, and $2.5 \mathrm{ml}$ of $\mathrm{FeCl}_{3} \cdot 6 \mathrm{H}_{2} \mathrm{O}$ solution. The mixed solution was incubated at $37^{\circ} \mathrm{C}$ for $30 \mathrm{~min}$ and was referred to as FRAP solution and then, Sample $(150 \mu \mathrm{l})$ along with $3 \mathrm{ml}$ of FRAP solution remained for $30 \mathrm{~min}$ in the dark place. Readings of the colored product (ferrous-tripyridyltriazine complex) were then taken at $593 \mathrm{~nm}$. The $1 \mathrm{mmol} / 1$ FeSO4 was used as the standard solution. For the construction of the calibration curve, five concentrations of $\mathrm{FeSO}_{4} \cdot 7 \mathrm{H}_{2} \mathrm{O}(1000,750,500,250$, and 125 
$\mu \mathrm{mol} / \mathrm{l})$ were used and the absorbance was taken as a sample solution. The data were expressed as $\mu \mathrm{mFe}^{3+}$ that reduced to $\mathrm{Fe}^{2+}$ form per 1 .

\section{Determination of EY}

The EY of samples was measured to the following formula (Eq.4)

$$
\mathrm{EY} \%=\frac{\mathrm{W} 1-\mathrm{W} 2}{\mathrm{~W} 1} * 100
$$

\section{EY: Extraction Yield}

$\mathrm{W}_{1}$ : the initial weight of the onion by-product before extraction

$\mathrm{W}_{2}$ : the weight of the onion by-product after extraction

\section{Quercetin content}

Quercetin content was carried out by the method of Chang et al. [24] with slight changes. The stock solutions were provided by $0.5 \mathrm{ml}$ quercetin solution that was provided in $0.1 \mathrm{ml}$ methanol. quercetin standard solutions were made, by using different dilutions $\left(5-200 \mu \mathrm{g} / \mathrm{ml}\right.$ methanol). Then, $0.6 \mathrm{ml} \mathrm{FeCl}_{3}$ solution was added to $0.6 \mathrm{ml}$ solution of quercetin standard. The solution was placed at room temperature for $60 \mathrm{~min}$ and was referred to as quercetin solution [25]. To prepare the sample, $1.10 \mathrm{~g}$ of extract of onion by-products were mixed to $4 \mathrm{cc}$ ethanol solu-

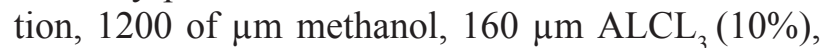
$160 \mu \mathrm{m}$ potassium acetate 1 molar and 2080 of $\mu \mathrm{m}$ distilled water, Finally, kept at room temperature for $40 \mathrm{~min}$ and absorbance of the sample was calculated at $415 \mathrm{~nm}$ according to the following formula (Eq.5).

$$
\mathrm{Q}=(\mathrm{A}-0.0596 / 89.663) * 100000
$$

$$
\begin{aligned}
& \mathrm{A}=(\text { Asample }- \text { Acount }) \\
& \mathrm{Q}: \text { quercetin content }(\mathrm{mg} / 100 \mathrm{~g}) \\
& \mathrm{A}_{\text {Count: }} \text { absorbance value of control } \\
& \mathrm{A}_{\text {Sample: }} \text { absorbance value of sample }
\end{aligned}
$$

\section{Results and discussion}

\section{Model fitting}

The effect of two independent variables consists of the PV and NP in the PEF assisted extraction process on the dependent variables including determining the EY \%, DPPH \%, FRAP $\mu \mathrm{mol} \mathrm{Fe} / 1, \mathrm{TPC}, \mathrm{mg} /$ $\mathrm{kg}$ and quercetin $\mathrm{mg} / 100 \mathrm{~g}$ was evaluated. FCED was performed with five central points. In order to determine the experimental model for prediction of the response, polynomial equations including linear, two factorials, quadratic term, and third term, fitted on the data obtained from the Response Surface Methodology (RSM). Then, these models were statistically analyzed. It should be noted that the statistical model of adequate, is a model that lack of fit was not significant and has the highest $\mathrm{R}^{2}$ and Adj $\mathrm{R}^{2}$. The responses of the dependent variables derived from the experimental and predicted experiments through the Response Surface Methodology (RSM) are presented in Table 2. The observations in this Table are shown a very good correlation between the results obtained by the experimental method and the predicted values by the statistical method. Also, this model was used to evaluate the linear, quadratic, third terms effects of independent variables on dependent variables. Analysis of variance and regression were used to assay the correspondence of the proposed models and statistical analysis of the significant variables of the model.

Investigating the effect of independent variables on qualitative and quantitative properties of onion extract

\section{Determination of EY}

An empirical model was obtained for predicting responses, polynomial relationships including linear, two factorial, quadratic term, that were fitted to the data obtained from these responses (Table 2). Also, it was shown that the linear model was the best model for interpreting the effect of variables (PV, NP) on the EY. According to the analysis of variance, independent variables were PV and NP in the linear and quadratic model, that had significant statistical differences $(P<0.05)$. In the regression model, the $\mathrm{R}$-square $(0.710)$ was high and lack of fit was not significant $(P$ $<0.05$ ). These values provide an appropriate mathematical model. The relationship between extraction efficiency and experimental variables was presented .in Fig 1. The most EY content was achieved in the highest NM and PV. The combination of the two independent variables (NM, PV) can be expected to enhance the EY (Fig1). Also, the NP was increased (40 to 50V), and EY was increased with slight gradient and it's following, with more increasing of NP (50 to 60), the EY increased sharply. The highest EY $(92.66 \%)$ was at PV of $6000 \mathrm{~V}$ and NP of 40 Which it was probably due to the destruction of the internal structure and the electrical decomposition of the cells and their greater permeability [4;26]. As a consequence, the increase of the NP resulted in enhancement of the degradation coefficient of the treatments and extracted intracellular compounds from damaged cells. Researchers demonstrated that the EY of effective compounds from papaya seeds increased with elevation of the NP, which was in agreement with this research [27]. 


\begin{tabular}{|c|c|c|c|c|c|c|c|c|c|c|c|c|c|c|}
\hline 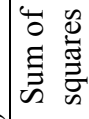 & $\begin{array}{l}\hat{\alpha} \\
\text { o. } \\
\text { di }\end{array}$ & $\mid \begin{array}{l}n \\
6 \\
6 \\
n\end{array}$ & $\begin{array}{l}\infty \\
\stackrel{f}{q} \\
\stackrel{f}{2}\end{array}$ & $\mathscr{Z}$ & $\mathscr{Z}$ & $\begin{array}{l}2 \\
\vdots \\
\hat{b}\end{array}$ & $\left.\mid \begin{array}{ll}0 \\
0 \\
0 \\
0 \\
0\end{array}\right]$ & & 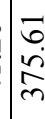 & & & & & \\
\hline 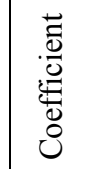 & $\begin{array}{l}\stackrel{*}{8} \\
\stackrel{8}{+} \\
\dot{\sim}\end{array}$ & 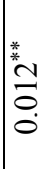 & 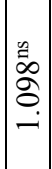 & $\mathscr{z}$ & $\stackrel{q}{a}$ & $\begin{array}{l}0 \\
\tilde{\delta} \\
\hat{i} \\
i\end{array}$ & & f & & 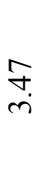 & $\begin{array}{l}\stackrel{R}{0} \\
\dot{\infty} \\
\infty\end{array}$ & & & 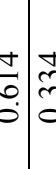 \\
\hline
\end{tabular}

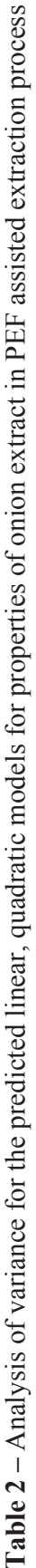

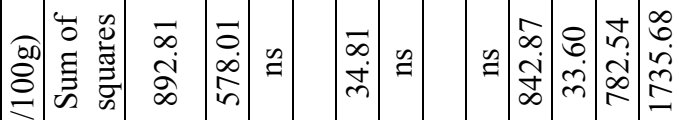

\begin{tabular}{|c|c|c|c|c|c|c|c|c|c|c|c|c|c|c|}
\hline$c_{000}=0$ & $\infty$ & in & & $m$ & & & 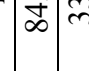 & & 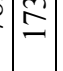 & & & & & \\
\hline 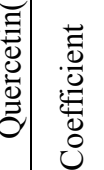 & 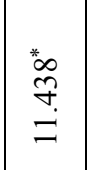 & $\mid \begin{array}{c}* \\
\stackrel{*}{*} \\
0 \\
0 \\
0\end{array}$ & $\mathscr{a}$ & 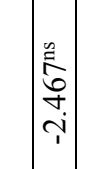 & $\cong$ & $\stackrel{2}{=}$ & $\tilde{g}$ & $\stackrel{f}{a}$ & & & & & $\begin{array}{l}0 \\
\\
0 \\
0\end{array}$ & 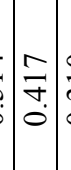 \\
\hline
\end{tabular}

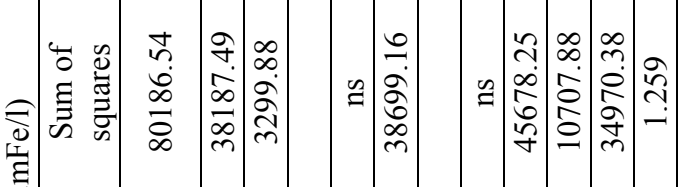

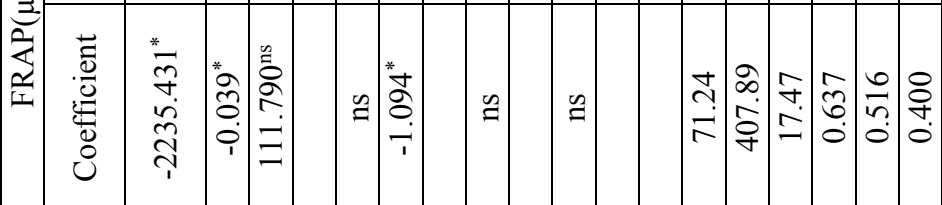

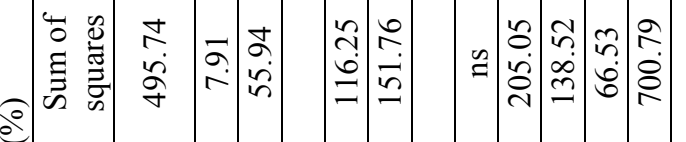

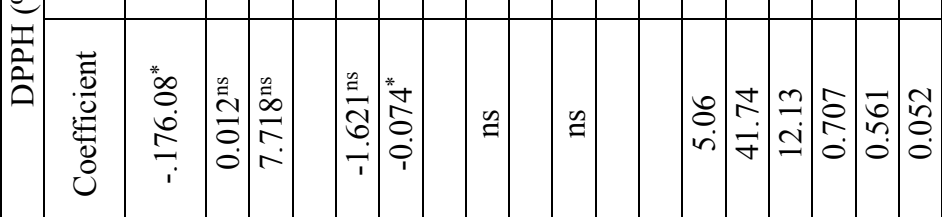

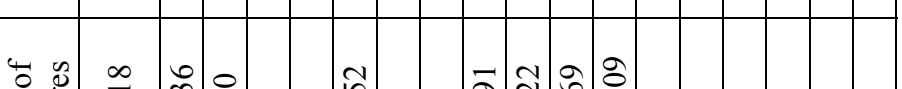

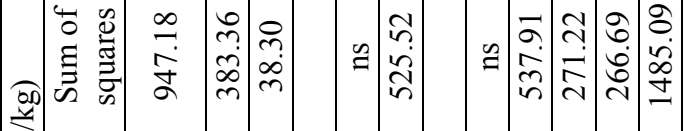

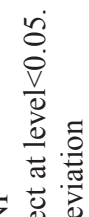

艺莺宫

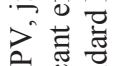

$\because$.

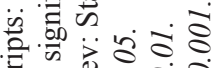

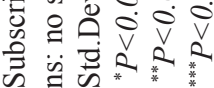




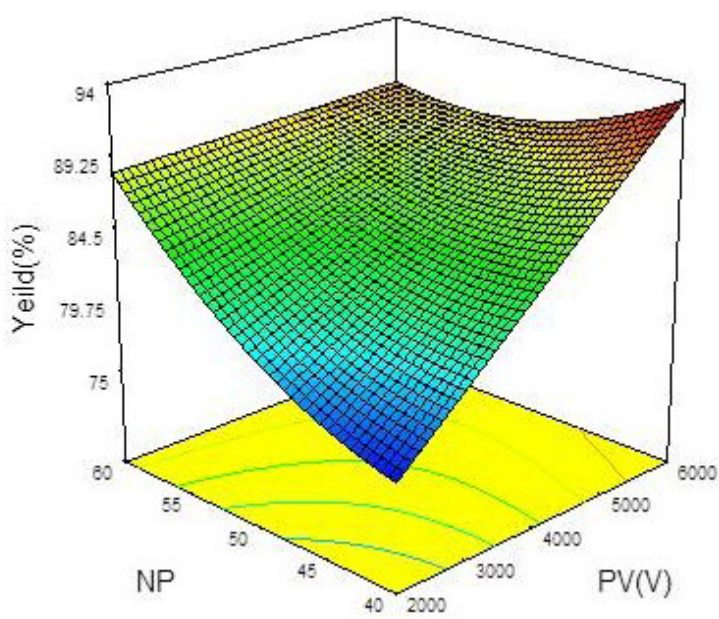

Figure 1 - Response surface plot of the EY of onion extraction as a function of PV and NP

\section{Effects of PV and NP on TPC extraction}

The analysis of variance of onion extract compounds by PEF in Table 2 was indicated. It can be considered that the linear coefficient of the NP, the quadratic term of PV and the interaction term coefficient were not significant $(P>0.05)$. In order to obtain an empirical model for predicting the response, linear and polynomial relations of the second order fitted on the provided data from the analysis. In this response, the coefficient of $\mathrm{R}^{2}$ of the predicted models (0.637) and $P$-Value for lack of fit for achieved model, was 0.595 , which declared that it had no significant effect $(P>0.05)$. These values presented an appropriate mathematical model. Fig 2, illustrated the NP was an effective factor in the efficiency and selectivity of the extraction technique. The PV parameter on the TPC was a significant effect $(P<0.05)$, so that, the TPC decreased with the promotion of the PV from 2000 to $6000 \mathrm{~V}$. In conformity with Fig 2, the TPC extraction increased with the elevating the NP from 40 to 50 that caused to damage to the cell membrane and ultimately, extracted more TPC. While with a further increasing NP until 60, the TPC extraction was decreased. As it can be described, Increasing PV and NP (50 to 60) were reduced TPC extraction that Due to the decomposition effect of high PV on TPC. These results presented similar behavior with the issues of Bobinaie et al. [28] which depicted that expansion of the field intensity from 1 to $5 \mathrm{kV} / \mathrm{m}$ caused in a significant increase in TPC extraction $(P<0.05)$, as well as, a slight decrease in the amount of phenolic compounds in the blueberry fruit and its by-products, when there was the highest flow intensity $(5 \mathrm{kV} / \mathrm{cm})$. In fact, they showed that the more intensity above $1 \mathrm{kV} / \mathrm{cm}$ for fresh blueberry fruit did not increase

Int. j. biol. chem. (Online) the release of TPC in the juice. Also, Toepfi et al. [29] exposed that the high electric field intensity above $300-500 \mathrm{~V} / \mathrm{cm}$ for texture of many fruits and vegetables, reduced amount of yield and damaged to the tissues [21], also increased the electric pulse field intensity that the created irreversible damages to the cell membrane and it's following caused irreversible permeability and more extraction of TPC into solvent [26].

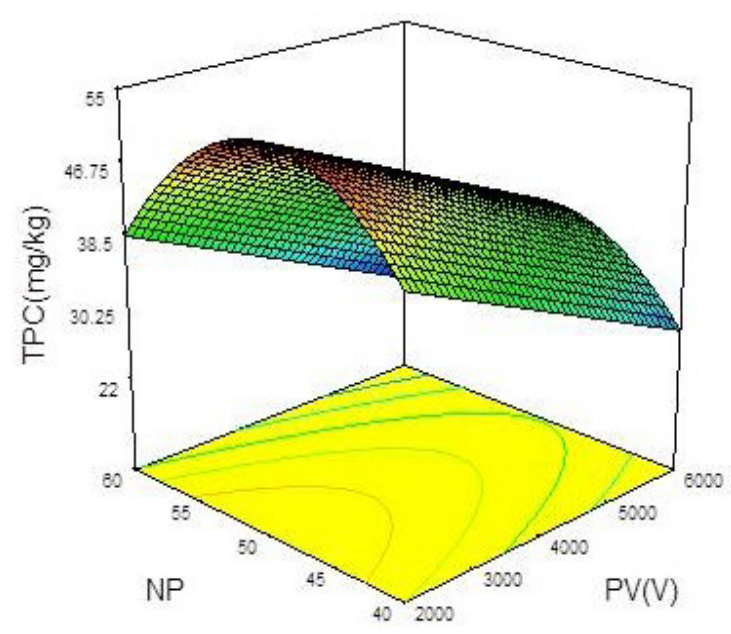

Figure 2 - Response surface plot of the total phenolic compound (TPC) of onion extract as a function of PV and NP

\section{Effects of $P V$ and NP on antioxidant activity} $D P P H$ radical-scavenging capacity

The antioxidant activity evaluation is dependent on the ability of DPPH as a stable free radical to bleach in the presence of antioxidants. Therefore, the less value of DPPH exhibited the high ability of the extract to inhibit free radicals activities [30]. The results of Table 2 declared that in the linear model and the interaction term, independent variables (PV and NP) had not a significant effect on DPPH radical-scavenging capacity $(P>0.05)$. In the second order, the independent variable of NP demonstrated a clear significant effect on DPPH radical-scavenging capacity $(P<0.05)$. In the regression model, $\mathrm{R}^{2}(0.770)$ was highly significant. Based on response surface Fig 3, the increase in $\mathrm{PV}$ from 2000 to $4000 \mathrm{~V}$, resulted in an increase in DPPH (38.71\%). While the further increase in PV up to $6000 \mathrm{~V}$, caused a decrease in DPPH (27.63\%). By increasing the NP from 40 to 50 , DPPH value, raised (50.98\%), and then, extending the NP, until 60 , could lead to declining the DPPH value (35.72\%). According to researches by 
Anagnostopoulou et al. [31]. There was a direct relationship between TPC and antioxidant activity. In this study, The NP of 40 and the PV of $4000 \mathrm{~V}$ had the highest TPC, antioxidant strength of the extract (Fig 3) due to increase the permeability and release of TPC, and therefore the DPPH radicalscavenging strength. Rocco et al; Csepregi et al. $[32 ; 33]$ stated that there was a high correlation between the TPC content and antioxidant activity of the extract, that it was in agreement with this research. The information of Table 2 indicated that the model fitted to the data obtained for independent variables, in the study condition, exactly and with high accuracy, the ability to fit the data. The high $\mathrm{CV}, \mathrm{R}^{2}$ and Adj $\mathrm{R}^{2}$ confirmed model has adequate fit to the observed data.

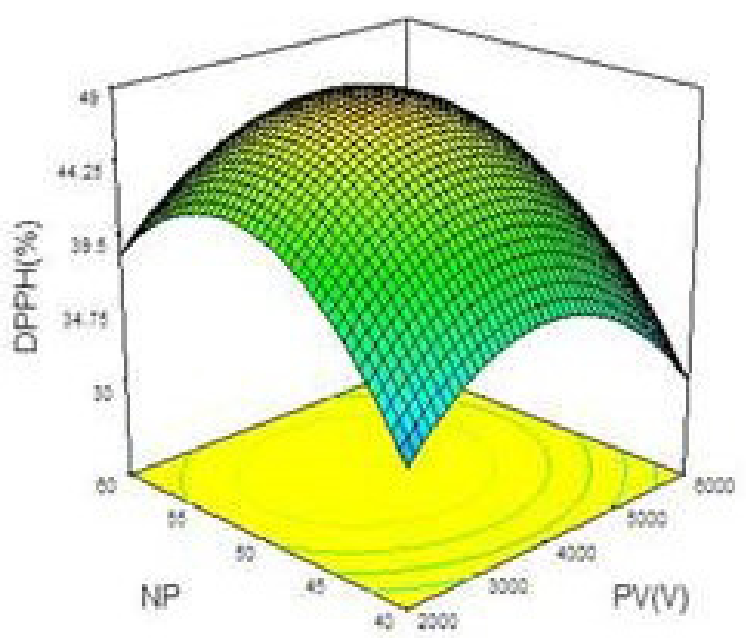

Figure 3 - Response surface plot of the DPPH of onion extract as a function of PV and NP

\section{Ferric reducing/antioxidant power criterion}

Reduction of $\mathrm{Fe}^{+3}$ is often used as an indicator of electron reduction capability, which is an important mechanism in the antioxidant action of phenolic compounds [34]. The antioxidant capacity of onion extract was determined by the antioxidant ability. In these extracts, the reduction of the $\mathrm{Fe}^{+3}$ to $\mathrm{Fe}^{+2}$ by the FRAP reagent was observed. The results of Table 2 showed that in the linear term, PV and in quadratic term NP were significant $(P<0.05)$. In the interaction term, independent variables (PV, NP) were not significant $(P>0.05)$. it can be seen in Fig 4 when the PV go to increase (2000 to $6000 \mathrm{~V})$, the FRAP started to decrease, while FRAP initially increased and then decreased as the NP raised from 40 to 50 , due to the thermal decomposition of the antioxidant compounds of susceptible [35;36]. Since the PV (4000 V) and the
NP (50) were, the highest FRAP content, was 549.15 $\mu \mathrm{M} \mathrm{Fe}^{+2 /,}$ whereas the PV $(6000 \mathrm{~V})$ and the NP (40) were, the lowest FRAP content was purposed 252.15 $\mu \mathrm{M} \mathrm{Fe}{ }^{+2 / .}$ In the regression model, lack of fit was significant $(P<0.05)$ and its $C V$ was $(17 / 47)$, which confirmed the power of this model.

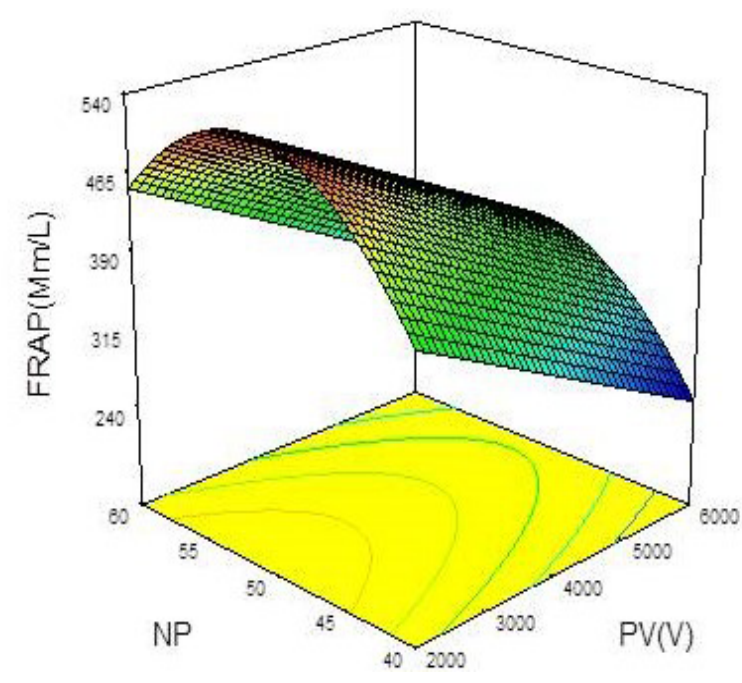

Figure 4 - Response surface plot of the FRAP of onion extract as a function of PV and NP Effects of PV and NP on Quercetin content

The analysis of variance Table 2 illustrated that in linear coefficient, only, PV on the quercetin extraction was significant $(P<0.05)$. While in the quadratic term, the interaction effect, the independent variables (PV, NP) did not have a significant effect on the quercetin content $(P>0.05)$. Regression model had a relatively suitable $\mathrm{R}$-square $\left(\mathrm{R}^{2}=\right.$ 0.514). Based on the sum of squares, the independent variable in the quadratic term was PV. As it can be shown in Fig 5, the PV parameter had the greatest effect on quercetin content and caused a significant increase $(P<0.05)$ in quercetin extraction. Since quercetin is a heat-resistant flavonoid compound [37], therefore, when the PV increased to $4000 \mathrm{~V}$, the solubility and was enhanced. The results of other researchers on Inga edulis plant leave were in agreement with this study [38]. Also, considering the significance of the second order term the PV parameter, exhibited that by increasing the PV to $4000 \mathrm{~V}$ and the NP to 50 , the highest quercetin extraction content $(47.88 \mathrm{mg} / 100 \mathrm{~g})$ was obtained. As the PV exceeds up to $4000 \mathrm{~V}$, quercetin content decreased sharply.

This effect can be attributed to the increase in PV and hence the thermal degradation of this composi- 
tion. The results of this study coincided with earlier researchers [39]. Regarding the evaluation of the proposed model in Table 2 for the quercetin content, it was clear that the predicted relationship between the $\mathrm{R}^{2}$ and the Adj $\mathrm{R}^{2}$ were proportional and significant $(P<0.01)$.

The lack of fit was not significant $(P>0.05)$ and its CV was (34/34), which confirmed the strength of this model.

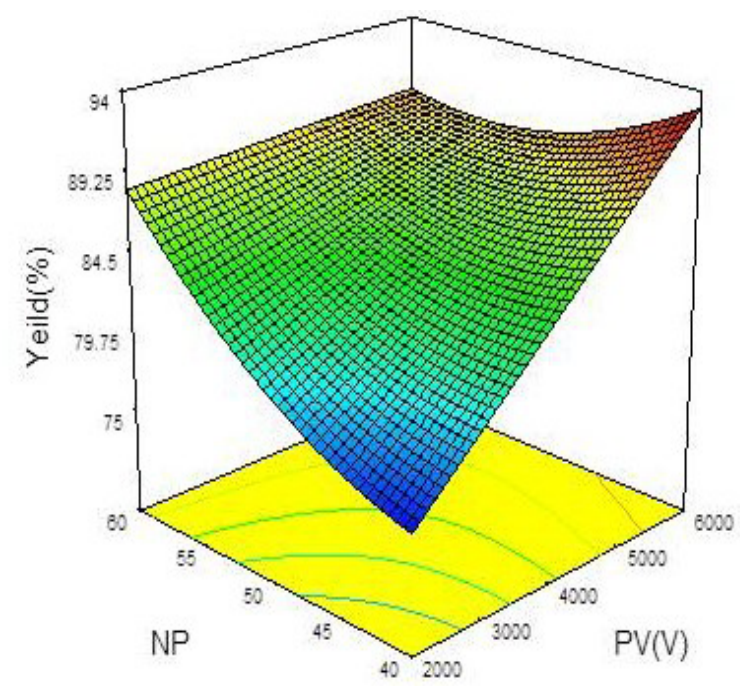

Figure 5 - Response surface plot of the Quercetin conten onion extract as a function of PV and NP
Optimization comparison PEF-assisted extraction with conventional extraction

Considering the best extraction condition of onion extract by PEF treatment that was based on the study of the PV from 2000 to $6000 \mathrm{~V}$ and the NP from 40 to 60 , the extraction process was optimized for all response variables in order to determine the maximum of EY, TPC and antioxidant strength. Characteristics of phenolic antioxidants found out by PEF process and under optimal condition were compared with conventional extraction (Table 3 ). The results Table 3 showed that to achieve the above objectives, the PV and NP should be $4102.97 \mathrm{~V}$ and 51.43 respectively. Under these terms, the quercetin content, DPPH, EY, TPC and FRAP were $31.76 \mathrm{mg} / 100 \mathrm{~g}$, $50.36 \%, 88.10 \%, 48.91 \mathrm{mg} / \mathrm{kg}, 465.41 \mu \mathrm{mFe}^{2+} / 1$, sequentially. To evaluate the accuracy of the optimized process, the proposed treatment was produced under the same conditions as the other treatment, and the results of TPC content, DPPH, FRAP, Quercetin content compared with the predicted results by model. There was no significant difference $(P>0.05)$ between actual and empirical observations. (Table 3 ). Also, the desirability was achieved at $628 \%$ (Fig 6). PEF method gave a higher amount of the TPC, DPPH, FRAP, Quercetin content and EY than the conventional extraction method. PEF is more effective than the conventional method in maximizing characteristics of antioxidant compounds. Thus, this method can cause an increase in mass transfer.

Table 3 - Actual and predicted values of the response variables at optimal conditions for PEF and conventional methods

\begin{tabular}{|c|c|c|c|}
\hline \multirow{2}{*}{ Characteristics } & Extraction Method & & Conventional \\
\cline { 2 - 4 } & PEF & & Actual values \\
\cline { 2 - 4 } & Predicted values & Actual values & $21.234^{\mathrm{b}} \pm 3$ \\
\hline TPC $(\mathrm{mg} / \mathrm{kg})$ & $46.881^{\mathrm{a}}$ & $48.912^{\mathrm{a}} \pm 6$ & $26.544^{\mathrm{b}} \pm 1$ \\
\hline DPPH $(\%)$ & $49.544^{\mathrm{a}}$ & $50.366^{\mathrm{a}, \mathrm{a}} \pm 1$ & $398.112^{\mathrm{b}} \pm 0.2$ \\
\hline FRAP $\left.(\mu \mathrm{mFe})^{2+} / 1\right)$ & $460.322^{\mathrm{a}}$ & $465.414^{\mathrm{a}} \pm 5$ & $18.566^{\mathrm{b}} \pm 0.1$ \\
\hline Quercetin $(\mathrm{mg} / 100 \mathrm{~g})$ & $30.666^{\mathrm{a}}$ & $31.761^{\mathrm{a}} \pm 0.5$ & $62.097^{\mathrm{b}} \pm 2$ \\
\hline $\mathrm{EY}(\%)$ & $87.110^{\mathrm{a}}$ & $88.107^{\mathrm{a}} \pm 1$ & \\
\hline
\end{tabular}

Mean \pm standard deviation

\section{Conclusion}

In this research, the quality properties of onion extract evaluated by PEF assisted extraction. The novel method of PEF was a rapid process and was known as one of the best environmentally friendly extrac- tion methods due to low solvent consumption, low environmental pollution. This process had a positive effect on the antioxidant activity of the extract. The response surface analysis of the FCED contains two independent variables: PV and NP were performed as effective and important parameters on the extrac- 
tion of antioxidant compounds of onion extract by PEF process. The results showed that the Response Surface Methodology (RSM) can be used to evaluate the EY. Both of the PV and NP was increased the antioxidant activity of the treatments.

Also, in the linear term, the PV in some cases, such as EY, TPC, Quercetin and FRAP and in the second order the NP has been affected on the TPC, FRAP, and DPPH. The proposed models in this research explained $\mathrm{R}^{2}$ and Adj $\mathrm{R}^{2}$. Also, the lack of fit was not significant and the low CV relatively indicated that the model was suitable for predicting the parameters. Additionally, optimization of PV and NP can produce high and adequate extract value by PEF assisted extraction, using this regression model, Enhanced antioxidant power, TPC and EY along with acceptable quercetin content showed the superiority of this new extraction technique to the conventional method. Therefore, we can predict and correct the required conditions by using the PEF assisted extraction method.

\section{Acknowledgment}

The authors are appreciated from the Agricultural Engineering Research Department, Khorasan Razavi Agricultural and Natural Research and Education, AREEO Mashhad, Iran, due to financial support throughout the research.

Abbreviation
CV Coefficient of Variation
DPPH 2, 2-diphenyl-1-picrylhydrazyl
EY Extraction Yield
FCED Face Centered Experimental Design
FRAP Ferric Reducing-Antioxidant Power
NP Number of Pulse
PEF Pulsed Electric Field
PV Pulse Voltage
TPC Total Phenolic Compounds

\section{References}

1. Hertog, Michael GL, Peter CH Hollman, Martijn B. (1992), Journal of agricultural, and food chemistry, 40, no. 12, P. 2379-83.

2. Tepe, Bektas, Dimitra Daferera, Atalay Sokmen, Munevver Sokmen, and Moschos, Polissiou (2005), J Food chemistry, 90, no. 3, P. 333-40.

3. Shon, Mi-Yae, Sang-Do Choi, Goon-Gjung Kahng, Sang-Hae Nam, Nak-Ju, Sung (2004), J Food and Chemical Toxicology, 42, no. 4, P. 659-66.
4. Ko, Min-Jung, Chan-Ick Cheigh, Sang-Woo Cho, and Myong-Soo Chung (2011), Journal of Food Engineering, 102, no. 4, P. 327-33.

5. Turner, Charlotta, Pernilla Turner, Gunilla Jacobson, Knut Almgren, Monica Waldebäck, Per Sjöberg, Eva Nordberg Karlsson, and Karin E, Markides (2006), J Green Chemistry, 8, no. 11, P. 949-59.

6. Vergara-Salinas, José R, Jara Pérez-Jiménez, Josep Lluís Torres, Eduardo Agosin, José R, PérezCorrea (2012), Journal of agricultural and food chemistry, 60, no. 44, P. 10920-29.

7. Yang, Bao, Yueming Jiang, John Shi, Feng Chen, and Muhammad (2011), J Food Research International Ashraf, 44, no. 7, P. 1837-42.

8. Chan, Chung-Hung, Rozita Yusoff, GekCheng Ngoh, and Fabian Wai-Lee (2011), Journal of Chromatography, 1218, no. 37, P. 6213-25.

9. Azmir, Jannatul, ISM Zaidul, Rahman, MM., Sharif, KM., Mohamed, A., Sahena, F., Jahurul, MHA., et al. (2013), Journal of Food Engineering, 117, no. 4 426-36.

10. Wang, Lijun, Curtis L (2006), Trends in Food Science, 17, no. 6: 300-12.

11. Smith, Roger M (2003), Journal of chromatography A, 1000, no. 1-2, P. 3-27.

12. Barbosa-Cánovas, Gustavo V, Usha R Pothakamury, M Marcela Gongora-Nieto, and Barry G Swanson (1999) Preservation of Foods with Pulsed Electric Fields, Elsevier.

13. Barbosa-Cánovas, Gustavo V, María S Tapia, and M Pilar Cano (2004), Novel Food Processing Technologies. CRC press.

14. Donsì, Francesco, Giovanna Ferrari, and Gianpiero, Pataro. (2010), J Food Engineering Reviews, 2, no. 2, P. 109-30.

15. Grimi, Nabil, Nikolai I Lebovka, Eugene Vorobiev, and Jean Vaxelaire (2009), J Food Biophysics, 4, no. 3, P. 191-98.

16. Corramles, M, S Toepfl, P Butz, D Knorr, B, Tausche. (2008), J Innovative Food Science and Emerging Technologies, 9, P. 85-91.

17. Luengo, Elisa, Ignacio Álvarez, Javier, Raso (2013), J Innovative Food Science and Emerging Technologies, 17 79-84.

18. Wijngaard, H., Hossain, M. B., Rai, D. K., \& Brunton, N. (2012), J Food Research International, 46(2), P. 505-513.

19. Rouhani, Sh, Valizadeh, N and Salimi, Sh. (2009), Progress in color colorants and coatings, 2 , no 2, P. 103-113. 
20. Azarpazhooh, Elham, Hosahalli S (2012), $J$ Food and bioprocess technology, 5, no. 5 1486501.

21. Singleton, Vernon L, Rudolf Orthofer, and Rosa M Lamuela-Raventós (1999), In Methods in Enzymology, Elsevier, "Analysis of Total Phenols and Other Oxidation Substrates and Antioxidants by Means of Folin-Ciocalteu Reagent", P.152-78.

22. Ersus, S., Yurdagel, U. (2007), Food Engineering, 80, P.805-812.

23. Benzie, Iris FF, and Strain, J. (1999), In Methods in Enzymology, "Ferric Reducing/Antioxidant Power Assay: Direct Measure of Total Antioxidant Activity of Biological Fluids and Modified Version for Simultaneous Measurement of Total Antioxidant Power and Ascorbic Acid Concentration", Elsevier, P. 15-27.

24. Chang, Chia-Chi, Ming-Hua Yang, HweiMei Wen, Jiing-Chuan, Chern. (2002), Journal of food and drug analysis, 10, no. 3 .

25. Chandra, Suman, Shabana Khan, Bharathi Avula, Hemant Lata, Min Hye Yang, Mahmoud A ElSohly, Ikhlas A, Khan. (2014), Evidence-Based Complementary and Alternative Medicine. "Assessment of Total Phenolic and Flavonoid Content, Antioxidant Properties, and Yield of Aeroponically and Conventionally Grown Leafy Vegetables and Fruit Crops: A Comparative Study.”.

26. Lebovka, NI, MI Bazhal, and E, Vorobiev. (2002), Journal of Food Engineering, 54, no. 4, P. 337-46.

27. Bobinaite,, Ramunè, Gianpiero Pataro, Nerijus Lamanauskas, Saulius Šatkauskas, Pranas Viškelis, Giovanna, Ferrari. (2015), Journal of food science and technology, 52, no. 9, P. 5898-905.
28. Toepfl, S, V Heinz, D, Knorr. (2007), Chemical engineering and processing: Process Intensification, 46, no. 6, P. 537-46.

29. Amarowicz, R, RB Pegg, P Rahimi-Moghaddam, B Barl, and JA, Weil. (2004), Food chemistry, 84, no. 4, P. 551-62.

30. Anagnostopoulou, Maria A, Panagiotis Kefalas, Vassilios P Papageorgiou, Andreana N Assimopoulou, and Dimitrios, Boskou. (2006), Food chemistry, 94, no. 1, P. 19-25.

31. Csepregi, Kristóf, Susanne Neugart, Monika Schreiner, and Éva, Hideg. (2016), Molecules, 21, no. 2, P. 208.

32. Rocco, A., Fanali, C., Dugo, L. and Mondello L. (2014), Electrophoresis, 35(11), P. 1701-1708.

33. Nabavi, S.M, Ebrahimzadeh, M.A., Nabavi, S.F., Hamidinia, A. and Bekhradnia, A.R., (2008), Pharmacologyonline, no.2, P. 560-567.

34. Ahmadian-Kouchaksaraie, Zahra, Razieh Niazmand, Masoud Najaf-Najafi. (2016), Innovative food science and emerging technologies, no. 36, P. 234-44.

35. Vergara-Salinas, José R, Jara Pérez-Jiménez, Josep Lluís Torres, Eduardo Agosin, José R, PérezCorrea. (2012), Journal of agricultural and food chemistry, 60, no. 44, P. 10920-29.

36. Everaldo Moreira, José Maria Barbosa Filho, Ticiano Gomes do Nascimento, and Rui Oliveira, Macêdo. (2002), Thermochimica Acta, 392, P. 79-84.

37. Silva, EM, JNS Souza, H Rogez, JeanFrançois Rees, and Yvan, Larondelle. (2007), Food Chemistry, 101, no. 3, P. 1012-18.

38. Aoyama, Sakiko, Yukiko, Yamamoto. (2007), Food science and technology research, 13, no. 1, P. 67-72. 